\title{
Bactericidal effect of plasma jet with helium flowing through 3\% hydrogen peroxide against Enterococcus faecalis
}

\author{
XIN-CAI ZHOU ${ }^{1 *}$, YU-LAN LI $^{1 *}$, DE-XI LIU ${ }^{2}$, YING-GUANG CAO ${ }^{2}$ and XIN-PEI LU ${ }^{3}$ \\ ${ }^{1}$ Department of Stomatology, Baoan Maternal and Child Health Hospital, College of Medicine, Jinan University, \\ Shenzhen, Guangdong 518133; ${ }^{2}$ Department of Stomatology, Tongji Hospital, \\ Tongji Medical College, Huazhong University of Science and Technology, Wuhan, Hubei 430030; \\ ${ }^{3}$ College of Electrical and Electronic Engineering, Huazhong University of Science and Technology, \\ Wuhan, Hubei 430074, P.R. China
}

Received June 30, 2015; Accepted August 23, 2016

DOI: $10.3892 /$ etm.2016.3726

\begin{abstract}
The aim of the present study was to assess the antimicrobial activity of plasma jet with helium (He) flowing through 3\% hydrogen peroxide in root canals infected with Enterococcus faecalis. A total of 42 single-rooted anterior teeth were prepared, sterilized, inoculated with an E.faecalis suspension and incubated for 7 days. Next, the teeth were randomly divided into six experimental groups (including groups treated by plasma jet with or without He for different time durations) and one control group treated without plasma. The number of surviving bacteria in each canal was determined by counting the colony forming units $(\mathrm{CFU}) / \mathrm{ml}$ on nutrient agar plates. The results indicated that statistically significant reduction in $\mathrm{CFU} / \mathrm{ml}(\mathrm{P}<0.005)$ existed for all treatment groups relative to the control group. The greatest reductions in $\mathrm{CFU} / \mathrm{ml}$ were observed for Group 3 (7.027 log unit reduction) and Group 2 (6.237 log unit reduction), which were treated by plasma jet sterilization with He flowing through $3 \%$ hydrogen peroxide for $4 \mathrm{~min}$ or for $2 \mathrm{~min}$, respectively. In addition, the reduction in Group 3 was significantly greater compared with that in Group 2 or in the groups treated by plasma jet sterilization without He flowing through $3 \%$ hydrogen peroxide for 1, 2 or $4 \mathrm{~min}$. In conclusion, plasma jet with or without He flowing through $3 \%$ hydrogen peroxide can effectively sterilized root canals infected with E. faecalis and should be considered as an alternative method for root canal disinfection in endodontic treatments.
\end{abstract}

Correspondence to: Dr Ying-Guang Cao, Department of Stomatology, Tongji Hospital, Tongji Medical College, Huazhong University of Science and Technology, 1095 Jiefang Road, Wuhan, Hubei 430030, P.R. China

E-mail: caoyguang2@163.com

*Contributed equally

Key words: antimicrobial efficacy, plasma jet, hydrogen peroxide, Enterococcus faecalis

\section{Introduction}

Bacteria and their products are major etiologic factors in pulpal and periapical pathosis $(1,2)$. It has also been shown that periapical inflammation does not occur in the absence of microorganisms, regardless of the quality of the root canal filling (3). Enterococci are commensal microorganisms that are found in the mucosal tissues of the oral cavity, gastrointestinal tract and genital tract in humans (4). Enterococci are of clinical importance since they are the third most common nosocomial pathogens (5) and the cause of refractory apical periodontitis (6). They are often resistant to germicides and antiseptics as they can persist under harsh conditions, such as high alkalinity, due to their efficient use of proton pumps (7). To date, 12 enterococci species have been identified, and $\sim 90 \%$ of the Enterococcus clinical isolates are of the Enterococcus faecalis species (8).

E. faecalis can survive various extreme environmental conditions and for long periods of time under nutritional deprivation. In addition, it has been shown to be resistant to the calcium hydroxide treatment that is commonly used in the course of endodontic therapy (9). Endodontic therapy mainly attempts to eliminate bacteria from the root canal. The use of chemical irrigation and mechanical instrumentation along with medication of the root canal system between treatment sessions can significantly reduce the population of bacteria inside the infected root canal (10). However, eradication of all bacteria from the root canal system is difficult $(11,12)$.

Plasmas have been used for a number years for the disinfection of medical equipment, implants, blood coagulation and tooth bleaching (13-20). Chen et al reported that $\mathrm{He} / \mathrm{O}_{2}$ plasma more effectively killed $E$. faecalis than pure He plasma (21). Recently, our group designed a special low-temperature plasma device that generates plasma plumes in open space (surrounding air), rather than only in a confined discharge gap (22). This low-temperature plasma device has been used in previous studies to efficiently kill E. faecalis bacteria $(19,20,22,23)$. The aim of the present study was to assess the antimicrobial activity of the plasma jet device with He flowing through 3\% hydrogen peroxide in root canals infected with E.faecalis. 


\section{Materials and methods}

Experimental setup. Fig. 1 shows the plasma jet device with the working gas flowing through $3 \%$ hydrogen peroxide, which is used in the treatment of a root canal infected with E. faecalis. The inner diameter of the syringe nozzle was $\sim 1.0 \mathrm{~mm}$. When the root canals were treated, the syringe nozzle was vertically put on the root-canal orifice. The working gas used in all the experiments was He with a flow rate of $2 \mathrm{l} / \mathrm{min}$. All the experiments in the present study used the same frequency of $8 \mathrm{kHz}$, applied voltage of $8 \mathrm{kV}$ and pulse width of 1,600 ns.

Microbial preparation. E. faecalis (ATCC 29212; American Type Culture Collection, Manassas, VA, USA) were grown in Müller-Hinton (M-H) agar (Difco Laboratories, Detroit, MI, USA), and incubated overnight at $37^{\circ} \mathrm{C}$. The microorganisms were then inoculated into a test tube containing $2 \mathrm{ml}$ sterile physiological saline. The suspension was adjusted to a turbidity of $6.0 \times 10^{8}$ colony forming units (CFU)/ml. Subsequently, the same amount of brain heart infusion (BHI) broth (Difco Laboratories) was added to the test tube. At this point, the concentration of bacteria was $3.0 \times 10^{8} \mathrm{CFU} / \mathrm{ml}$ (equivalent to $1.0 \mathrm{McF}$ arland unit).

Preparation of teeth. The study protocol was reviewed and approved by the Ethical Review Board of Investigation at the Tongji Hospital of Huazhong University of Science and Technology (Wuhan, China). Informed consent was obtained from the patients. A total of 42 extracted, human single-rooted anterior teeth with curvatures between 0 and 10 degrees were obtained and stored in physiological saline. The external root surface was cleaned with curettes to remove periodontal soft tissues and calculus. All root canals were prepared in a crown-down technique with K-file (Dentsply Maillefer, Ballaigues, Switzerland) and ProTaper instruments (Dentsply Maillefer) by an experienced endodontist and the size of ProTaper files included sizes 10/15/SX/S1/S2/F1/F2 and F3. Next, the teeth were placed in an ultrasonic bath in $17 \%$ ethylenediaminetetraacetic acid for $5 \mathrm{~min}$, followed by $5.25 \%$ sodium hypochlorite for a further $5 \mathrm{~min}$ in order to remove the smear layer. Root canals were then rinsed with sterile water and placed in an ultrasonic cleaner for $20 \mathrm{~min}$. Next, all teeth were autoclaved for $30 \mathrm{~min}$ at $121^{\circ} \mathrm{C}$, and parafilm was used to seal all the apical foramina of root canals. A sterile micropipette was used to introduce $10 \mu \mathrm{l}$ of the bacterial suspension into each root canal, and root canal orifices were sealed with parafilm. Subsequently, the teeth were incubated aerobically at $37^{\circ} \mathrm{C}$ for 7 days. After 3.5 days of incubation, $10 \mu \mathrm{l} \mathrm{BHI}$ broth was introduced into each root canal. Following the incubation, the root canals were blotted dry with size 40 sterile paper points.

The teeth were randomly divided into one control and six experimental groups (6 teeth in each group), according to the various times and methods of plasma sterilization. The groups were as follows: Plasma jet sterilization with He flowing through $3 \%$ hydrogen peroxide for $1 \mathrm{~min}$ (Group 1), 2 min (Group 2) or 4 min (Group 3); plasma jet sterilization without $\mathrm{He}$ gas flowing through 3\% hydrogen peroxide for 1 min (Group 4), 2 min (Group 5) or 4 min (Group 6); and He gas flowing at 2 1/min for 4 min with the plasma off (Group 7; control group).
After the treatment, an experienced endodontist used a new sterile ProTaper file with size F3 to manually file the root canal of each tooth, with each root canal filed 20 times. The parafilm was removed from the root canal orifice, and the tooth and debris in each file were irrigated with $1 \mathrm{ml}$ sterile physiological saline from the apical foramen to the root canal orifice. Subsequently, the debris was collected in a test tube and agitated with adding sterile physiological saline to $5 \mathrm{ml}$. Serial dilutions (X10) of the samples were plated onto M-H agar and the plates were incubated at $37^{\circ} \mathrm{C}$ for $48 \mathrm{~h}$. The number of $\mathrm{CFU} / \mathrm{ml}$ was then obtained for each sample by an observer in a blinded manner.

Optical emission spectra. To identify the various reactive species generated, the optical emission spectrum of plasma jet without or with He flowing through 3\% hydrogen peroxide is measured in the 200-1,100 nm wavelength range. A spectrometer (Acton SP-2500i; Princeton Instruments, Acton, MA, USA) was used to measure the emission spectra of the plasma jet with or without the He gas flowing through $3 \%$ hydrogen peroxide.

Scanning electron microscopy. A total of $100 \mu \mathrm{l}$ of the bacterial suspension were seeded on two sterile cellulose nitrate membrane filters (Merck Millipore, Billerica, CA, USA), which were placed in BHI broth and incubated at $37^{\circ} \mathrm{C}$ for $72 \mathrm{~h}$ in an aerobic atmosphere. The experimental group membrane was treated by plasma jet sterilization with $\mathrm{He}$ gas flowing through $3 \%$ hydrogen peroxide at $21 / \mathrm{min}$ for $2 \mathrm{~min}$. The control group membrane was treated with He gas flowing at $21 / \mathrm{min}$ for $4 \mathrm{~min}$ with the plasma off. Subsequently, the two membranes were fixed with $2.5 \%$ glutaraldehyde, rinsed with distilled water and dehydrated in a series of ethanol. The two dried specimens were coated with gold and then observed under scanning electron microscopy (JEOL JSM-6700F system; JEOL, Tokyo, Japan).

Statistical analysis. Data are expressed as the mean \pm standard deviation. SPSS software, version 17.0 (SPSS, Inc., Chicago, IL, USA) was used to analyze the data. Cell counts were logarithmically converted prior to statistical comparison. Kruskal-Wallis test and Mann-Whitney analysis were used to determine the differences in bactericidal efficacy. Statistically significant differences among the groups were considered at P-values of $<0.01$.

\section{Results}

Antibacterial effects of the plasma jet with and without He flowing through 3\% hydrogen peroxide. Fig. 2 demonstrates the results of the antibacterial effects of the plasma jet with and without He flowing through $3 \%$ hydrogen peroxide. Overall, the viable count of E. faecalis was significantly decreased $(\mathrm{P}=0.001)$ in all plasma treatment groups relative to the control group. However, the antibacterial effects of the plasma jet with He flowing through $3 \%$ hydrogen peroxide were better when compared with the effect of the plasma jet without He. In addition, a longer sterilization time resulted in improved bactericidal effects of the treatment as observed by the decreased viable count of bacteria after treatment for 4 min (Fig. 2). The 


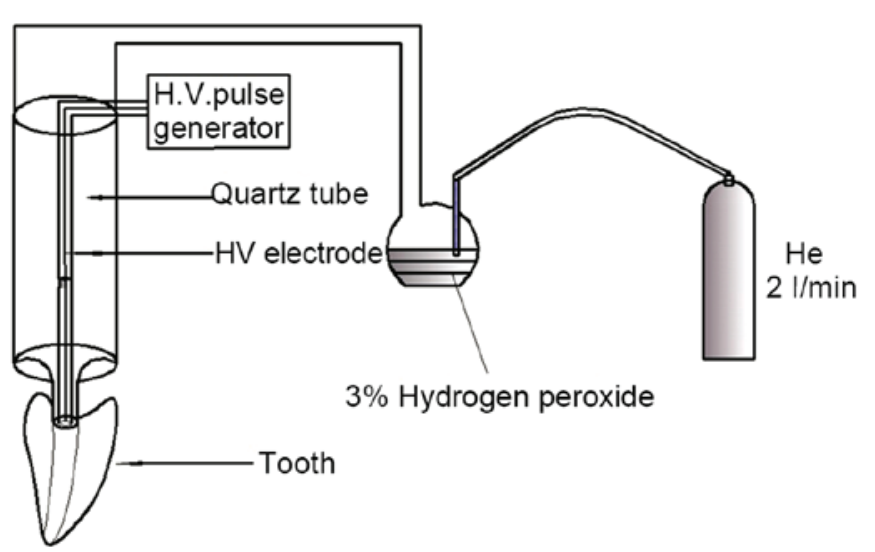

Figure 1. Plasma jet device with helium flowing through $3 \%$ hydrogen peroxide, used in the treatment of a rootcanal infected with Enterococcusfaecalis.

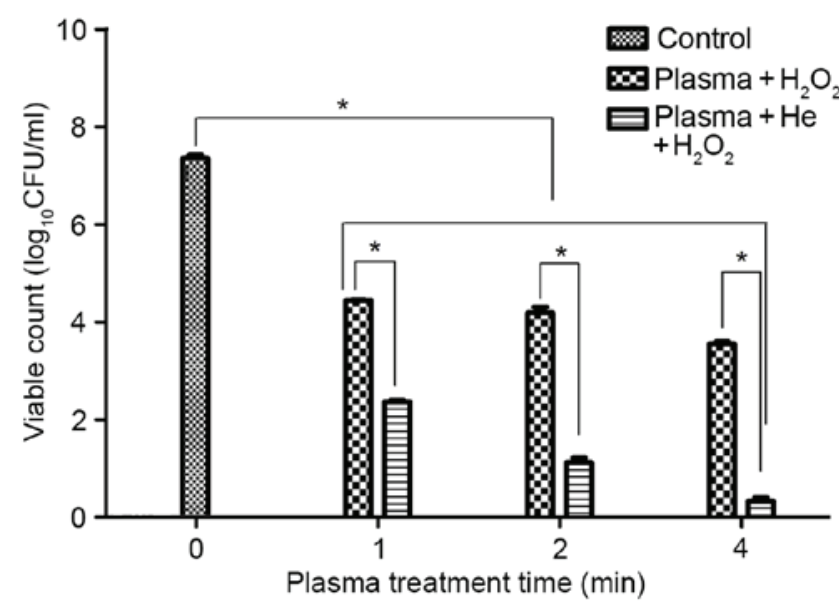

Figure 2. Survival of Enterococcus faecalis following treatment by plasma jet sterilization without or with He flowing through $3 \%$ hydrogen peroxide. ${ }^{*} \mathrm{P}<0.005$. He, helium.

greatest reduction in $\mathrm{CFU} / \mathrm{ml}$ was observed in Group 2 (plasma jet with He for $2 \mathrm{~min}$ ) and Group 3 (plasma jet with He for $4 \mathrm{~min}$ ), which presented a reduction by 6.237 and $7.027 \mathrm{log}$ units, respectively (Fig. 2). The reduction in the bacterial count observed in Groups 1, 2 and 3 (treated by plasma jet with $\mathrm{He}$ ) was significantly greater compared with that in Groups 4,5 and 6 , which were treated by plasma jet without $\mathrm{He}(\mathrm{P}<0.005)$. In addition, Group 3 showed a significant $\mathrm{CFU} / \mathrm{ml}$ reduction compared with Groups 1 and 2, which were treated by plasma jet with $\mathrm{He}$ for a shorter time length $(\mathrm{P}=0.0015, \mathrm{P}=0.002)$.

Optical emission spectra of plasma jet without or with He flowing through 3\% hydrogen peroxide. Fig. 3 demonstrates the optical emission spectra of plasma jet without or with $\mathrm{He}$ flowing through $3 \%$ hydrogen peroxide at wavelengths between 200 and $1,100 \mathrm{~nm}$. The spectra indicated that plasma jet with He flowing through $3 \%$ hydrogen peroxide presented stronger emission lines of atomic oxygen $(777.2 \mathrm{~nm})$ and hydroxyl radical $(309 \mathrm{~nm})$ compared with that in the plasma jet without He flowing through 3\% hydrogen peroxide (Fig. 3). The results indicated that reactive species, including atomic oxygen and hydroxyl radical, serve a dominant role in the plasma jet sterilization, whereas $\mathrm{N}_{2}$ and $\mathrm{He}$ are not expected to serve a significant direct role.
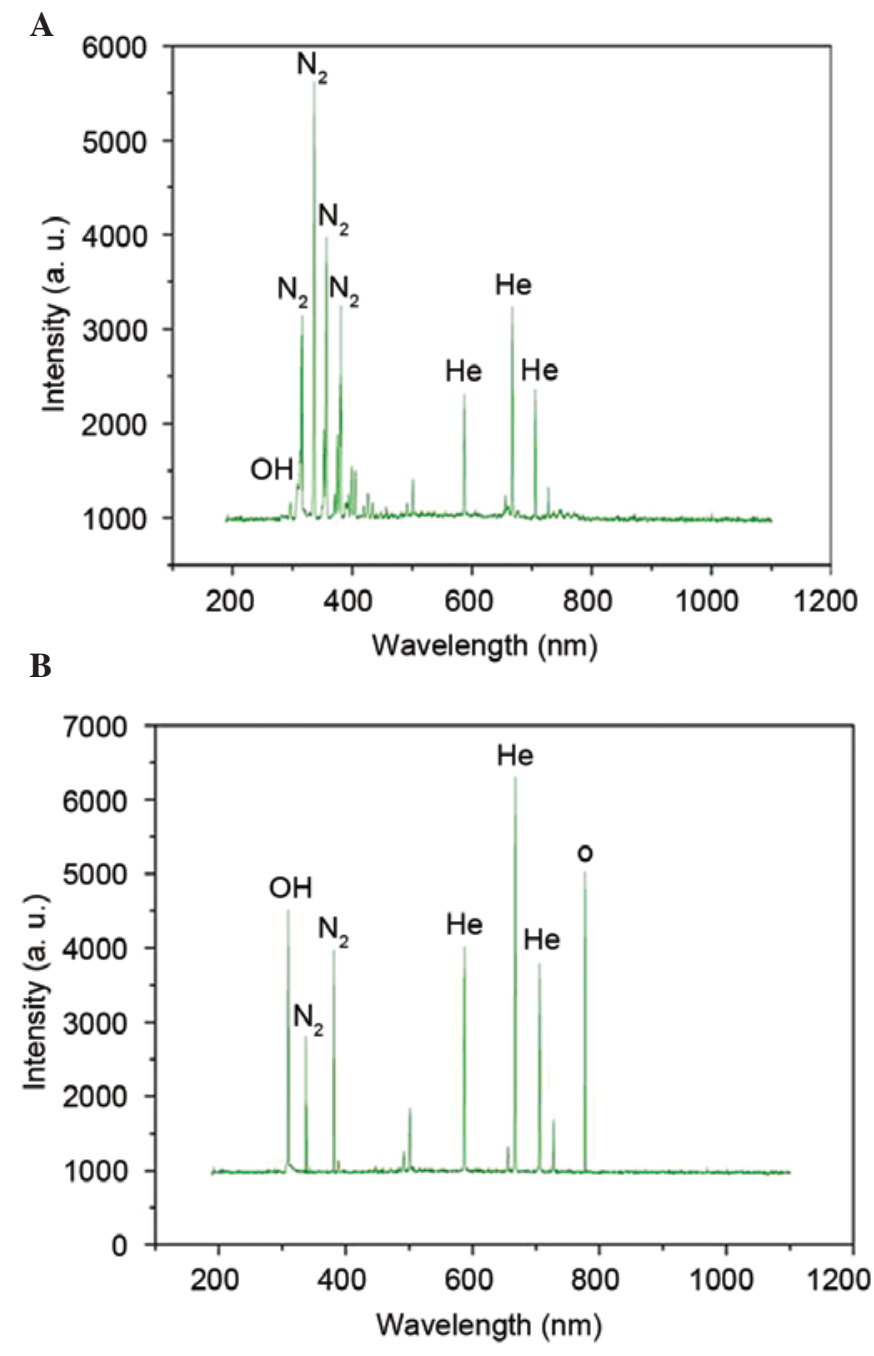

Figure 3. Optical emission spectra of plasma jet (A) without He and (B) with He flowing through $3 \%$ hydrogen peroxide. He, helium.

E. faecalis cells in Group 2 and the control group were investigated by scanning electron microscopy. As shown in Fig. 4, the images captured following plasma jet treatment demonstrated reduced size, rupture and death of E. faecalis cells, compared with the control cells. The results of scanning electron microscopy clearly explained the reduced viability of bacterial cells observed following treatment by plasma jet with He flowing through $3 \%$ hydrogen peroxide.

\section{Discussion}

E.faecalis was selected as the test microorganism in the present study owing to its high frequency of isolation from cases of failed endodontic treatment. E. faecalis had been shown to have a high affinity for biofilm formation, and bacteria in the biofilm form were up to 1,000 -fold more resistant to phagocytosis, antibodies and other antibiotics compared with those in the planktonic form (24).

In the present study, Groups 3 and 2 treated by plasma jet with He flowing through $3 \%$ hydrogen peroxide produced a 7.027 and 6.237 log reduction, respectively, in the bacterial CFU, when compared with the control group. This result suggests that the E. faecalis biofilms were eradicated in Groups 3 and 2. The 

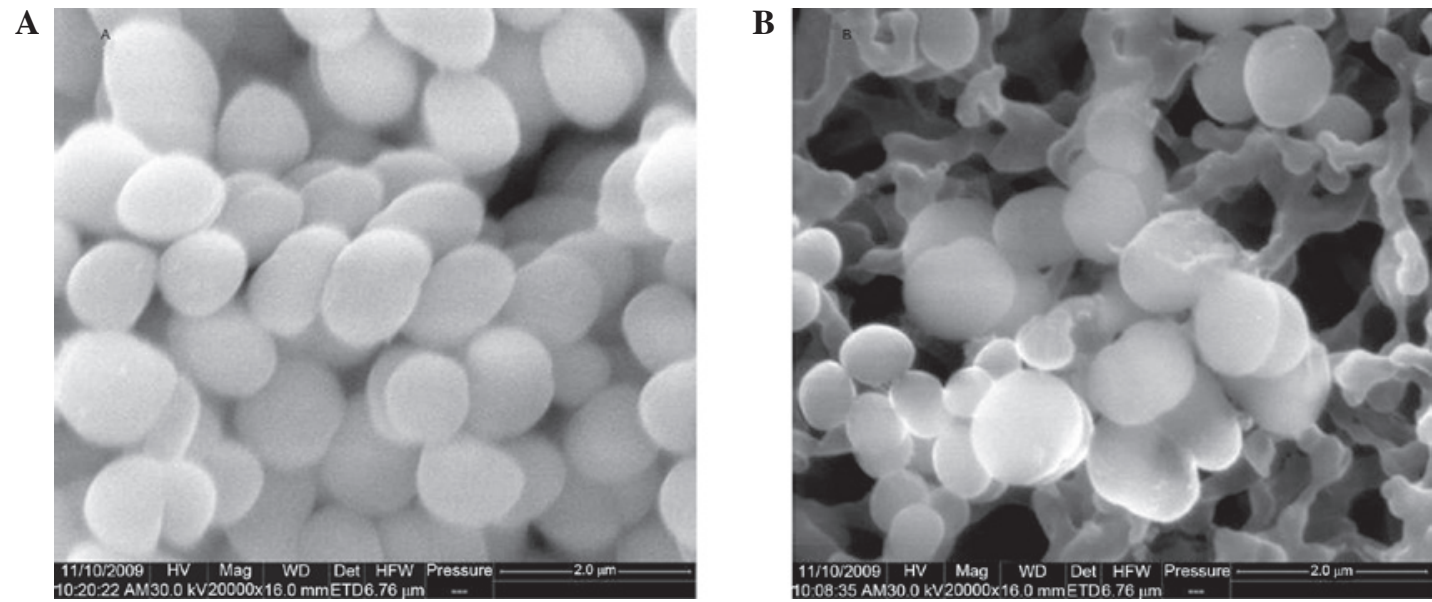

Figure 4. Scanning electron microscope images of Enterococcus faecalis cells, obtained (A) prior to plasma treatment and (B) after 2-min treatment by plasma jet with He flowing through $3 \%$ hydrogen peroxide (magnification, x20,000).

other experimental groups obtained reductions of at least $2.909 \log$ units. Therefore, the results in all groups were promising.

The bactericidal effect of the plasma jet with or without He flowing through $3 \%$ hydrogen peroxide resulted mainly from the atomic and molecular radicals. Reactive oxygen species (ROS) are generally considered to serve a key role in the bactericidal process. Short-time plasma treatment can induce DNA fragmentation (25). The ROS are able to penetrate the cells and, therefore, may induce high levels of DNA damage, which then causes the induction of apoptosis $(26,27)$. Hydrogen peroxide is an oxidizing agent that leads to microbial death by protein denaturation. It is widely applied for disinfection processes in the food, water treatment, healthcare and contact lens industries (28). Hydrogen peroxide decomposition and the recombination of radicals can lead to the formation of molecular oxygen, atomic oxygen and hydroxyl radical $(29,30)$. In the present study, stronger emission lines of atomic oxygen and hydroxyl radical were detected in the plasma jet with He flowing through $3 \%$ hydrogen peroxide using a spectrometer, when compared with plasma jet without He flowing through $3 \%$ hydrogen peroxide. The atomic oxygen and hydroxyl radical are considered to be responsible for the improved antibacterial effects of the plasma jet with He flowing through $3 \%$ hydrogen peroxide when compared with the plasma jet without He. The results indicate that reactive species, including atomic oxygen and hydroxyl radical, serve a dominant role in the plasma jet sterilization, whereas $\mathrm{N}_{2}$ and $\mathrm{He}$ are not expected to serve a significant direct role, and these findings are consistent with the results of a previous study (31).

In the current study, the UV intensity emitted by the plasma jet with or without the working gas flowing through $3 \%$ hydrogen peroxide was detected, and it was found that the UV intensity was approximately $0.05-0.1 \mathrm{~mW} / \mathrm{cm}^{2}$. Therefore, the UV radiation served a minor role in the sterilization of the bacteria $(19,32)$. Heat was not responsible for the bactericidal effect, since the plasma jet with or without the working gas flowing through $3 \%$ hydrogen peroxide was at room temperature. Scanning electron microscopy was also used in the present study to reveal damage to E. faecalis by plasma jet with He flowing through $3 \%$ hydrogen peroxide. The obtained images of E. faecalis cells demonstrated reduction in size, rupture and death, when compared with the normal cells.

Single-rooted anterior teeth with curvatures between 0 and 10 degrees used in the present study were easily standardized to exclude interference of the dental anatomic complexity. Thus, further studies should examine the sterilizing effect of the plasma jet with He flowing through $3 \%$ hydrogen peroxide in complexity root canal systems.

In conclusion, the results of the present study suggested that the antibacterial effects of the plasma jet with He flowing through $3 \%$ hydrogen peroxide were better compared with the antibacterial effects of the plasma jet without He flowing through $3 \%$ hydrogen peroxide. The atomic oxygen and hydroxyl radical were considered to be responsible for the improved antibacterial effects of the plasma jet with He when compared with the plasma jet without He. The results also suggested that the plasma jet device with or without He flowing through $3 \%$ hydrogen peroxide is a valuable tool for root canal disinfection of E. faecalis, and that plasma treatment could be considered as an alternative method for root canal disinfection of $E$. faecalis in endodontic treatments.

\section{Acknowledgements}

The present study was supported by a grant from the Natural Science Foundation of China (grant no. 10875048).

\section{References}

1. Kakehashi S, Stanley HR and Fitzgerald RJ: The effects of surgical exposures of dental pulps in germ-free and conventional laboratory rats. Oral Surg Oral Med Oral Pathol 20: 340-349, 1965.

2. Möller AJ, Fabricius L, Dahlén G, Ohman AE and Heyden G: Influence on periapical tissues of indigenous oral bacteria and necrotic pulp tissue in monkeys. Scand J Dent Res 89: 475-484, 1981.

3. Fabricius L, Dahlén G, Sundqvist G, Happonen RP and Möller AJ: Influence of residual bacteria on periapical tissue healing after chemomechanical treatment and root filling of experimentally infected monkey teeth. Eur J Oral Sci 114: 278-285, 2006.

4. Walter J: Ecological role of lactobacilli in the gastrointestinal tract: Implications for fundamental and biomedical research. Appl Environ Microbiol 74: 4985-4996, 2008. 
5. Wisplinghoff H, Seifert H, Tallent SM, Bischoff T, Wenzel RP and Edmond MB: Nosocomial bloodstream infections in pediatric patients in United States hospitals: Epidemiology, clinical features and susceptibilities. Pediatr Infect Dis J 22: 686-691, 2003.

6. Hancock HH III, Sigurdsson A, Trope M and Moiseiwitsch J: Bacteria isolated after unsuccessful endodontic treatment in a North American population. Oral Surg Oral Med Oral Pathol Oral Radiol Endod 91: 579-586, 2001.

7. Evans M, Davies JK, Sundqvist G and Figdor D: Mechanisms involved in the resistance of Enterococcus faecalis to calcium hydroxide. Int Endod J 35: 221-228, 2002.

8. Gordon S, Swenson JM, Hill BC, Pigott NE, Facklam RR, Cooksey RC, Thornsberry C, Jarvis WR and Tenover FC: Antimicrobial susceptibility patterns of common and unusual species of enterococci causing infections in the United States. Enterococcal Study Group. J Clin Microbiol 30: 2373-2378, 1992.

9. Haapasalo M and Orstavik D: In vitro infection and disinfection of dentinal tubules. J Dent Res 66: 1375-1379, 1987.

10. Siqueira JF Jr, Rôças IN, Favieri A and Lima KC: Chemomechanical reduction of the bacterial population in the root canal after instrumentation and irrigation with 1\%,2.5\%, and 5.25\% sodium hypochlorite. J Endod 26: 331-334, 2000.

11. Nair PN, Henry S, Cano V and Vera J: Microbial status of apical root canal system of human mandibular first molars with primary apical periodontitis after 'one-visit' endodontic treatment. Oral Surg Oral Med Oral Pathol Oral Radiol Endod 99: 231-252, 2005.

12. Sjögren U, Figdor D, Persson S and Sundqvist G: Influence of infection at the time of root filling on the outcome of endodontic treatment of teeth with apical periodontitis. Int Endod J 30: 297-306, 1997.

13. Sladek REJ, Stoffels E, Walraven R, Tielbeek PJA and Koolhoven RA: Plasma treatment of dental cavities: A feasibility study. IEEE Trans Plasma Sci 32: 1540-1543, 2004.

14. Sladek REJ and Stoffels E: Deactivation of Escherichia coli by the plasma needle. J Phys D: Appl Phys 38: 1717-1721, 2005.

15. Stoffels E, Kieft IE and Sladek REJ: Superficial treatment of mammalian cells using plasma needle. J Phys D: Appl Phys 36 2908-2913, 2003.

16. Fridman G, Friedman G, Gutsol A, Shekhter AB, Vasilets VN and Fridman A: Applied plasma medicine. Plasma Process Polym 5: 503-533, 2008

17. Sun P, Pan J, Tian Y, Bai N, Wu H, Wang L, Yu C, Zhang J, Zhu W, Becker K and Fang J: Tooth whitening with hydrogen peroxide assisted by a direct-current cold atmospheric-pressure air plasma microjet. IEEE Trans Plasma Sci 38: 1892-1896, 2010 .
18. Lee HW, Nam SH, Mohamed AAH, Kim GC and Lee JK: Atmospheric pressure plasma jet composed of three electrodes: Application to tooth bleaching. Plasma Process Polym 7: 274-280, 2010

19. Zhou X, Xiong Z, Cao Y, Lu X and Liu D: The antimicrobial activity of an atmospheric-pressure room-temperature plasma in a simulated root-canal model infected with Enterococcus faecalis. IEEE Trans Plasma Sci 38: 3370-3374, 2010.

20. Cao Y, Yang P, Lu X, Xiong Z, Ye T, Xiong Q and Sun Z: Efficacy of atmospheric pressure plasma as an antibacterial agent against Enterococcus faecalis in vitro. Plasma Sci Tech 13: 93, 2011.

21. Chen W, Huang J, Du N, Liu XD, Wang XQ, Lv GH, Zhang GP, Guo LH and Yang SZ: Treatment of Enterococcus faecalis bacteria by a helium atmospheric cold plasma brush with oxygen addition. J Appl Phys 112: 013304, 2012.

22. Lu X, Xiong Z,Zhao F, Xiam Y, Xiong Q, Gong W, Zhou C, Jiang Z and Pan Y: A simple atmospheric pressure room-temperature air plasma needle device for biomedical applications. Appl Phys Lett 95: 181501, 2009.

23. Lu X, Cao Y, Yang P, Xiong Q, Xiong Z, Xian Y and Pan Y: An $R C$ plasma device for sterilization of root canal of teeth. IEEE Trans Plasma Sci 37: 668-673, 2009.

24. Distel JW, Hatton JF and Gillespie MJ: Biofilm formation in medicated root canals. J Endod 28: 689-693, 2002.

25. Kim GJ, Kim W, Kim KT and Lee JK: DNA damage and mitochondria dysfunction in cell apoptosis induced by nonthermal air plasma. Appl Phys Lett 96: 021502, 2010.

26. Buttke TM and Sandstrom PA: Oxidative stress as a mediator of apoptosis. Immunol Today 15: 7-10, 1994.

27. Simon HU, Haj-Yehia A and Levi-Schaffer F: Role of reactive oxygen species (ROS) in apoptosis induction. Apoptosis 5: 415-418, 2000

28. Heaselgrave W, Andrew PW and Kilvington S: Acidified nitrite enhances hydrogen peroxide disinfection of Acanthamoeba, bacteria and fungi. J Antimicrob Chemother 65: 1207-1214, 2010.

29. Soloshenko IA, Tsiolko VV, Khomich VA, Bazhenov VY, Ryabtsev A, Schedrin AI and Mikhno IL: Features of sterilization using low-pressure DC-discharge hydrogen-peroxide plasma. IEEE Trans Plasma Sci 30: 1440-1444, 2002.

30. Locke BR and Shih KY: Review of the methods to form hydrogen peroxide in electrical discharge plasma with liquid water. Plasma Sources Sci Technol 20: 34006-34020 (34015), 2011.

31. Wang D, Zhao D, Feng K, Zhang X, Liu D and Yang S: The cold and atmospheric-pressure air surface barrier discharge plasma for large-area sterilization applications. Appl Phys Lett 98: 161501, 2011.

32. Lu X, Ye T, Cao Y, Sun Z, Xiong Q, Tang Z, Xiong Z, Hu J, Jiang Z and Pan Y: The roles of the various plasma agents in the inactivation of bacteria. J Appl Phys 104: 053309, 2008. 